\title{
Entre rotinas e ritos, trabalho e festa: inventário das Folias de Reis fluminenses para registro como patrimônio cultural brasileiro
}

\author{
Between routines and rites, work and festivity: Folias de Reis in the State of Rio de Janeiro - \\ inventory for registration as a Brazilian cultural patrimony
}

Autores

Ricardo Gomes Lima. Diretor do Departamento Cultural da UERJ.

Email: ricgomeslima@terra.com.br

Thiago Silvestre da Silva. Estagiário de extensão UERJ.

Email: thiagosilvestre.geo@gmail.com

Recebido em: 26/01/2016 Aprovado em: 30/03/2017

DOI: $10.12957 /$ interag.2017.21032

\section{Relato}

\section{Resumo Abstract}

Este relato descreve o projeto Inventário Nacional de Referências Culturais das Folias de Reis do Estado do Rio de Janeiro, realizado a partir da assinatura do Termo de Cooperação Técnica firmado entre a UERJ e o Iphan/RJ. Respaldado na aplicação do Inventário Nacional de Referências Culturais - INRC, metodologia específica criada pelo Iphan, o projeto teve como objetivo fazer a identificação e a documentação da manifestação cultural conhecida como folia de reis, em território fluminense, a fim de construir referências atualizadas para subsidiar o potencial registro dessa expressão de cultura popular como um dos bens imateriais que constituem o patrimônio cultural brasileiro. A pesquisa foi desenvolvida em quinze municípios do
This report describes the project $\mathrm{Na}$ tional Inventory of Cultural References of the Folias de Reis of the State of Rio de Janeiro, made after the signing of the Term of Technical Cooperation between UERJ and Iphan / RJ. Backed by the application of the National Inventory of Cultural References - INRC, a specific methodology created by Iphan, the project aimed to identify and document the cultural manifestation known as Folias de Reis, in Rio de Janeiro, in order to construct updated references to subsidize the potential registration of this expression of popular culture as one of the intangible assets that constitute the Brazilian cultural heritage. The research was developed in fifteen municipalities of the State of Rio de Janeiro, members of the Program 
Estado do Rio de Janeiro integrantes do Programa de Aceleração do Crescimento das Cidades Históricas - PAC, programa federal que conta com a participação direta dos municípios e visa à preservação do patrimônio material e imaterial do país. Em 2016, os documentos gerados pelo INRC, incluindo o documentário etnográfico editado, foram concluídos e encaminhados ao Iphan, junto ao pedido de registro da folia de reis como patrimônio cultural do Brasil.

Palavras-chave: Patrimônio cultural. Tradição. Cultura Popular. Identidade. Folia de Reis. to Accelerate the Growth of Historic $\mathrm{Ci}$ ties - PAC, a federal program that has the direct participation of municipalities and aims at the preservation of the material and immaterial heritage of the country. In 2016, the documents generated by the INRC, including the edited ethnographic documentary, were completed and forwarded to Iphan, along with Folia de Reis' application for registration as a cultural patrimony of Brazil.

Keywords: Cultural patrimony. Tradition. Popular Culture. Folies de Reis. Identity

\section{Área temática: Cultura}

Linha de extensão: Propriedade intelectual e patente

\section{Introdução}

Foram os povos ibéricos que legaram ao Brasil a tradição das folias de reis. Os portugueses aqui chegados, nos primórdios da ocupação do território então conquistado, trouxeram na bagagem cultural hábitos e visões de mundo, incluindo sistemas de crença que orientam o modo do homem se relacionar com o mundo sobrenatural e também organizam as relações sociais que dão sentido à vida em sociedade e a regulamentam. Já àquela época, junto a um conjunto bastante amplo de prescrições, cerimônias e rituais, expressões da fé católica praticada pelo povo, encontra-se a devoção aos Santos Reis, assim denominadas as figuras bíblicas de Gaspar, Baltazar e Melquior. Diz-se mesmo que a história dos Reis Magos, pela teatralidade que permite ao ser encenada, foi apropriada pelos jesuítas como instrumento de catequese da população nativa ainda no século XVI. A Folia de Reis é uma expressão cultural que reproduz a saga dos Reis Magos à procura do Menino Deus. Possui um ciclo anual de ocorrência que comumente compreende o período de 24 de dezembro ao dia 6 de janeiro, dia de Santos Reis. Entretanto, em território fluminense, o ciclo costuma ser estendido até o dia 20 de janeiro, dia de São Sebastião, padroeiro da capital, de forte influência por todo o estado. ${ }^{1}$

Anualmente, no decorrer da efetivação da expressão cultural, os integrantes das folias de reis, autodenominados foliões, fardam-se e assumem personagens com funções e significados diversos, tais como mestre, contramestre, folião, bandeireiro ou bandeireira, músico e palhaço. Em território fluminense, na medida em que alguns personagens são representações dos soldados dos Reis Magos, ou mesmo os próprios reis, os 
últimos, os palhaços, são a personificação dos soldados do Rei Herodes em busca do Menino Deus a fim de matá-lo, o rei demoníaco ou mesmo o próprio diabo. Nesse sentido, os primeiros incorporam o papel do bem enquanto os palhaços são a personificação do mal. Sob a liderança do mestre, as folias de reis teatralizam a peregrinação dos Reis Magos do Oriente, valendo-se de entoação de cantos e de toques de instrumentos musicais como viola, sanfona, pandeiro, triângulo, chocalho e tambores. A cantoria da dramatização é composta por letras musicais inspiradas em textos bíblicos, que são transformados em poemas e declamados durante a performance da folia.

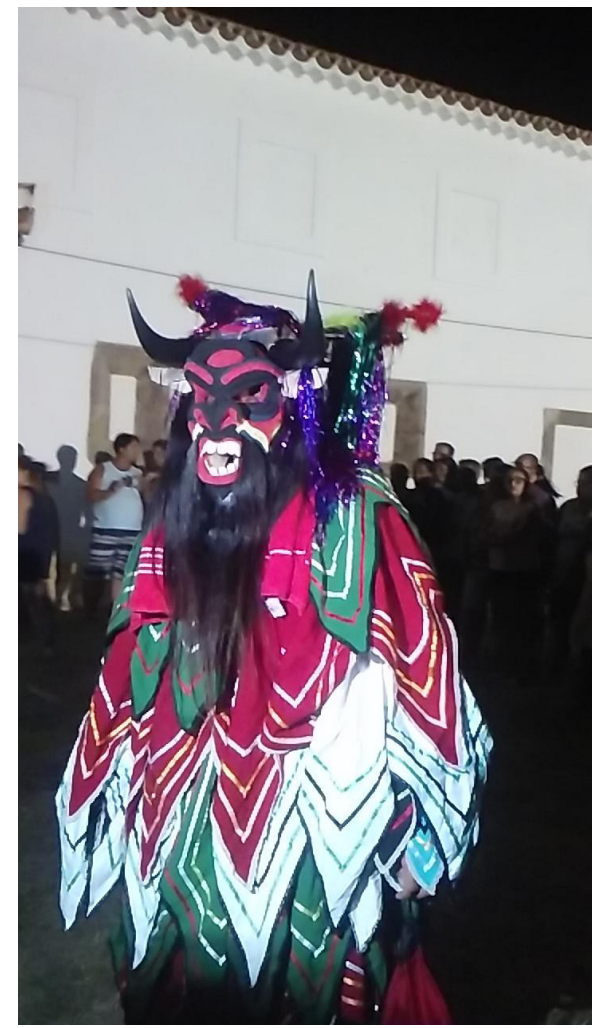

Palhaço da Folia de Reis Estrela do Oriente, Cabo Frio (RJ) - Janeiro/2016 Foto do arquivo pessoal do autor

Em diversos pontos do território brasileiro, registra-se a ocorrência da folia, "incorporada às dramatizações litúrgicas, com a participação do clero, nas igrejas do Brasil colônia, durante o Natal, Páscoa, Corpus Christi, Pentecostes e em festas de padroeiros de cidades, de corporações de profissionais, de grupos étnicos e sociais". ${ }^{2}$ Como se constituíssem uma família, enumeram-se as folias de reis, do Divino Espírito Santo, de São Benedito, de São Sebastião, de São José e várias outras. São grupos de base religiosa, comumente organizados por devoção ou pagamento de promessa que vão de porta em porta, visitando amigos e devotos e cantando louvores aos santos de sua devoção.

A folia de reis é uma dessas manifestações populares que tem origem no Reisado e está presente principalmente nas regiões Centro-Oeste e Sudeste do país. Embora pesquisas, como as de Amaral (1948)2 , Carneiro (1974) ${ }^{4}$ e Castro \& Couto (1977) ${ }^{5}$, apontem a origem rural da manifestação, é possível afirmar que a prática da Folia de Reis existe 
tanto no espaço rural como no espaço urbano há muito tempo. Como indagou o antropólogo Carlos Rodrigues Brandão: “De onde terá vindo a Festa de Santos Reis? Como ela terá chegado a ser um acontecimento de gente da roça, mesmo quando já migrada para as pontas de rua da cidade"6. Daniel Bitter, também antropólogo e pesquisador da cultura popular, observa que, na análise de Brandão predomina "a ideia de que a folia reconstituída em ambiente urbano já não é a mesma, sendo ela um sinal de reminiscência de uma sociabilidade estreitamente ligada a formas de vida camponesas"7.

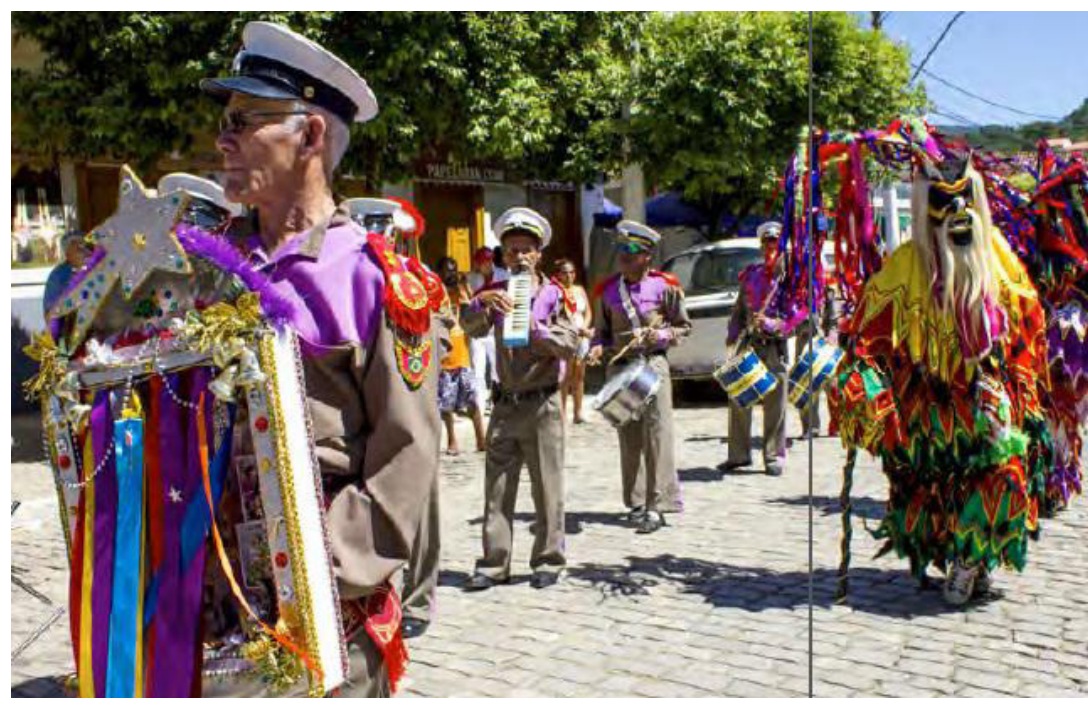

Folia de Reis Irmandade de Conselheiro, Duas Barras (RJ), 2011

Foto extraída do livro Folias de Reis na Serra Fluminense (2015), de Guilherme Lopes Moura.

Desse modo, está implícita na perspectiva de Carlos Rodrigues Brandão (1977) ${ }^{8}$ uma concepção de cultura como fenômeno social dinâmico relacionado a seu tempo, ou seja, não se pode mecanicamente atribuir o desaparecimento de tradições rurais ao processo de urbanização porque, conforme Laplantine, "as sociedades empíricas com as quais o etnólogo do século XX é confrontado não são nunca essas sociedades atemporais inencontráveis, ficticiamente arrancadas da história, e sim sempre sociedades em plena mutação" ${ }^{\prime \prime}$. Neste sentido, é possível entender a folia de reis como uma expressão cultural tradicional que acompanha o processo de transformação por que passa o Brasil. Muito presente no meio rural do Sudeste do país, a folia vem ganhando o espaço urbano desde as décadas de 1960 e 1970, quando se intensificou um massivo êxodo rural em direção às metrópoles.

\section{O projeto de inventário das folias de reis fluminenses: parceria UERJ-Iphan}

O projeto "Inventário Nacional de Referências Culturais das Folias de Reis do Estado do Rio de Janeiro" teve origem na assinatura de um Termo de Cooperação Técnica firmado, em 2010, entre a UERJ e o Iphan/RJ. Para realizar a sistematização das informações colhidas na pesquisa de campo foi utilizado o Inventário Nacional de Referências 
Culturais - INRC, uma metodologia de inventário de bens culturais criada pelo Iphan para subsidiar a execução do Programa Nacional do Patrimônio Imaterial (Decreto 3551/2000). O INRC é composto de três etapas de trabalho:

1) Levantamento Preliminar - definição da área a ser inventariada, sua subdivisão em localidades, reunião e sistematização de informações secundárias disponíveis; 2) Identificação - aprofundamento do conhecimento já produzido, isto é, das referências culturais listadas na etapa anterior; 3) Documentação - sistematização, interpretação do conhecimento produzido nas etapas anteriores e lançamento de seu resultado no sistema INRC. ${ }^{10}$

Nesse sentido, o projeto teve como objetivo fazer a identificação e a documentação da folia de reis em território fluminense, a fim de construir referências atualizadas para subsidiar o potencial registro dessa expressão de cultura popular como um dos bens imateriais que constituem o patrimônio cultural brasileiro.

Como uma ação da extensão, o projeto foi conduzido pelo Departamento Cultural da Sub-reitoria de Extensão e Cultura / UERJ, sob a direção do professor Ricardo Gomes Lima, contando com a supervisão de pesquisa da professora Cáscia Frade. Com apoio da Fundação Carlos Chagas Filho de Amparo à Pesquisa do Estado do Rio de Janeiro / Faperj, a pesquisa foi desenvolvida em quinze municípios do Estado do Rio de Janeiro integrantes do Programa de Aceleração das Cidades Históricas - PAC, programa federal que conta com a participação direta dos municípios e visa à preservação do patrimônio material e imaterial do país. Os municípios abrangidos pela pesquisa foram: Angra dos Reis, Cabo Frio, Casimiro de Abreu, Duas Barras, Itaboraí, Mangaratiba, Paraty, Petrópolis, Quatis, Quissamã, Rio Claro, Rio de Janeiro, Santa Maria Madalena, São Pedro d'Aldeia e Vassouras.

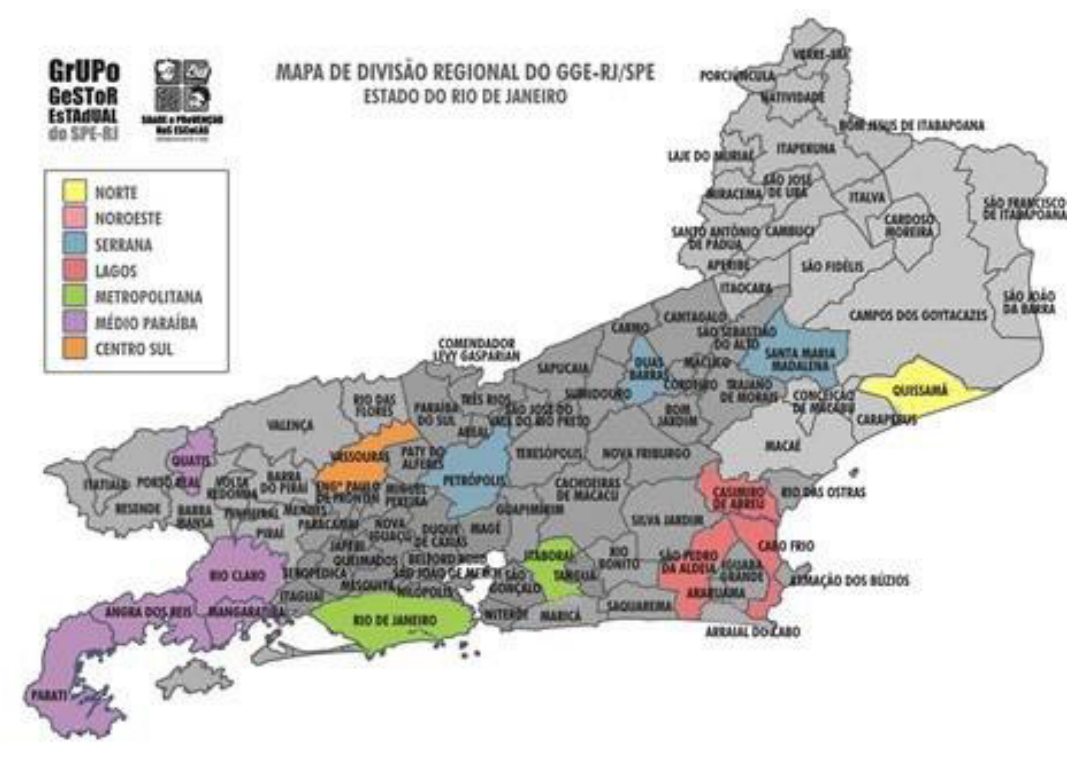

Mapa 1 - Municípios abrangidos pela pesquisa 
Para proceder à identificação e à atualização dos dados referentes aos grupos de folia de reis nos municípios inscritos no PAC, inicialmente foram realizadas pesquisas em acervos bibliográficos e audiovisuais, públicos e privados, tais como a Biblioteca Cândido Mendes (Universidade Cândido Mendes), bibliotecas universitárias da UERJ, UFF, UFRJ, UFRRJ, UNIRIO e PUC, Biblioteca Nacional, Centro Cultural Banco do Brasil (CCBB), Biblioteca Amadeu Amaral do Centro Nacional de Folclore e Cultura Popular (CNFCP/DPI/Iphan), biblioteca do Instituto Estadual do Patrimônio Cultural (INEPAC/ Departamento de Cultura/RJ), Biblioteca do Museu de História e Artes do Estado do Rio de Janeiro e sites de bancos de dissertações e teses.

Foram levantados 195 registros entre livros, publicações seriadas, textos inéditos, relatórios técnicos e manuscritos e 871 registros entre fotografias, audiovisuais, DVDs, fitas cassetes, gravações em vinil e outros.

Em seguida, foram estabelecidos contatos, via telefone e correio eletrônico, com instituições municipais relacionadas ao setor de cultura e informantes diversos residentes nos locais envolvidos, com vistas à obtenção de informações iniciais sobre os grupos presentes nas localidades definidas. Após identificados os grupos de folia de reis, a equipe formada por alunos universitários / estudantes bolsistas foi a campo, em visita aos municípios integrantes do projeto, objetivando a obtenção de informações etnográficas sobre a expressão cultural, in locu, orientada por um roteiro que reunia um conjunto de questões que objetivavam informações sobre o significado da prática para seus praticantes, os objetos simbólicos envolvidos, a organização do grupo, os modos de fazer o ritual e sua transmissão, os instrumentos do ofício e da realização da prática e a mobilização de recursos financeiros para manutenção da expressão.

Como o INRC é um modelo geral de inventário de bens culturais, sua aplicação adequada em cada caso implica na preparação da equipe envolvida no trabalho. O processo de preenchimento dos formulários foi marcado por reuniões na Superintendência do Iphan/RJ, com a participação da Assessoria do Patrimônio Imaterial daquele órgão, visando à orientação de utilização do modelo metodológico por parte daqueles alunos e pesquisadores diretamente engajados na pesquisa. Essa equipe foi formada basicamente por alunos/bolsistas dos cursos de graduação da UERJ que, além dos encontros no Iphan/RJ, participaram periodicamente de reuniões no Departamento Cultural/SR-3/ UERJ, para a concepção de ações que propiciassem melhor atendimento às normas do INRC e aos procedimentos relativos ao trabalho de campo.

Uma vez identificados os grupos de folia de reis ativos em todas as localidades eleitas, foi escolhido um deles em cada município para objeto de entrevista etnográfica mais detalhada. O critério de seleção obedeceu ao tempo de fundação dos grupos, dando prioridade para aqueles mais antigos, princípio combinado a outros critérios tais como anuência, disposição e disponibilidade de mestres e foliões para serem entrevistados. 


\begin{tabular}{|c|c|}
\hline Municipio & Grupo de folia de reis \\
\hline Angra dos Reis & $\begin{array}{l}\text { Folia de Reis Irmãos Moreira } \\
\text { Folia de Reis Sagrada Família } \\
\text { Folia de Reis de Bracuí } \\
\text { Folia de Reis Divino Espírito Santo } \\
\text { Folia de Reis Luz Divina (entrevistada) }\end{array}$ \\
\hline Cabo Frio & Folia de Reis Estrela D'Alva (entrevistada) \\
\hline Casimiro de Abreu & Folia de Reis Estrela Guia (entrevistada) \\
\hline Duas Barras & Folia de Reis Estrela do Dia (entrevistada) \\
\hline Itaboraí & $\begin{array}{l}\text { Folia de Reis Bandeira dos Três Reis do Oriente } \\
\text { (entrevistada) }\end{array}$ \\
\hline Mangaratiba & $\begin{array}{l}\text { Folia de Reis Os Três Reis do Oriente } \\
\text { (entrevistada) } \\
\text { Folia de Reis de Jacarei }\end{array}$ \\
\hline Paraty & Folia de Reis Estrela do Oriente (entrevistada) \\
\hline Petrópolis & Folia Três Reis Magos do Oriente (entrevistada) \\
\hline Rio Claro & Folia de Reis João Alves e Filho (entrevistada) \\
\hline Rio de Janeiro & $\begin{array}{l}\text { Folia de Reis Sagrada Família (entrevistada) } \\
\text { Folia de Reis Manjedoura da Mangueira } \\
\text { Folia de Reis Manjedoura de Belém } \\
\text { Folia de Reis Estrela do Oriente do Catumbi } \\
\text { Folia de Reis Jornada Estrela da Guia } \\
\text { Folia de Reis Estrela do Oriente } \\
\text { Folia de Reis Bandeira Cruzeiro do Sul do Méier } \\
\text { Folia de Reis Penitentes do Santa Marta }\end{array}$ \\
\hline Santa Maria Madalena & $\begin{array}{l}\text { Folia de Reis Estrela do Oriente (entrevistada) } \\
\text { Folia de Reis Estrela da Guia Vassouras } \\
\text { Folia de Reis Jornada Viagem dos Três Reis } \\
\text { (entrevistada) } \\
\text { Folia de Reis Jornada Família do Oriente } \\
\text { Folia de Reis Jornada Sábios do Oriente } \\
\text { Folia de Reis Boas Novas de Belém } \\
\text { Folia de Reis Divino Espírito Santo } \\
\text { Folia de Reis Jornada Estrela Real do Mankusi } \\
\text { Folia de Reis Jornada de Santos Reis Família } \\
\text { Teixeira } \\
\text { Folia de Reis Jornada Estrela Guia Do Oriente } \\
\text { Folia de Reis Jornada Jardim do Éden } \\
\text { Folia de Reis Jornada Estrela de Jacó }\end{array}$ \\
\hline Vassouras & $\begin{array}{l}\text { Folia de Reis Viagem dos Três Reis } \\
\text { (entrevistada) }\end{array}$ \\
\hline
\end{tabular}

Tabela 1 - Relação de grupos de folias de reis por município

Em relação a esse quadro, é importante registrar que não foram localizados grupos de folia de reis nos municípios de Quatis, Quissamã e São Pedro da Aldeia, embora sejam esses municípios integrantes do PAC das Cidades Históricas e, como tal, fazerem parte do universo da pesquisa. 
É importante destacar que a pesquisa de campo talvez seja o momento mais significativo para a formação do estudante/bolsista, na lida com a realidade social, uma vez que viabiliza o contato imediato com o objeto de estudo, além de ser a etapa em que o bolsista exerce mais ativa e diretamente a ação de extensão.

A respeito da pesquisa de campo etnográfica, o etnólogo Malinowski ${ }^{11}$ afirmou que seu objetivo fundamental deve ser a definição das leis e padrões de todos os fenômenos culturais, destacando-os de fatos irrelevantes. Segundo Malinowski ${ }^{11}$, o pesquisador de campo deve desenvolver a "observação participante", isto é, manter contato direto com o objeto de estudo para garantir boas condições de trabalho. Neste sentido, cada pesquisa de campo com os grupos de folia de reis contribuiu para aperfeiçoar a "observação participante" dos alunos engajados e, por conseguinte, a compreensão da importância do debate sobre o patrimônio artístico e cultural do Brasil e seus desdobramentos tanto para os grupos de folia de reis como para a sociedade brasileira como um todo.

Na perspectiva da formação do corpo discente da UERJ diretamente voltado para o projeto, a pesquisa de campo serviu para somar com demais experiências acumuladas durante o preenchimento do inventário, como discussões de textos no Departamento Cultural, reuniões de discussões metodológicas no Iphan/RJ, investigação de fontes secundárias, levantamento de dados antes e durante a realização da pesquisa de campo e participação em eventos relacionados a folias de reis em geral, como a "Festa do Remate" da Folia de Reis Sagrada Família, da Mangueira, na cidade do Rio de Janeiro. Com efeito, todas essas experiências tiveram um impacto sobre a formação dos graduandos envolvidos, das diferentes áreas: geografia, artes, letras, física e filosofia. De modo geral porque, como afirmou o estudante do Instituto de Geografia, "em parte das fichas que compõem o INRC, pode ser identificado um ou mais campos que guardam ligação com a geografia, como mapas, plantas, paisagem natural e meio ambiente, geografia da população e marcos edificados. Além disso, a própria seleção dos elementos em cada um desses campos foi marcada por discussões onde o raciocínio geográfico teve importância fundamental" (Thiago Silvestre - depoimento).

Por outro lado, fazer parte do processo de inventário de uma manifestação cultural permite ao aluno ter consciência política da importância do registro do patrimônio imaterial que, por ser transmitido de geração a geração, demanda preservação contínua. Além disso, inventariar manifestações culturais nos leva a entender como os bens materiais e imateriais interagem na formação da identidade e cidadania e na construção de um patrimônio cultural. Por essa razão, o mapeamento de grupos de cultura popular, como a folia de reis, é importante para o reconhecimento da expressividade cultural das camadas populares no conjunto das manifestações culturais que contribuem para a constituição do rico mosaico que compõe o patrimônio cultural brasileiro.

Pesquisas realizadas ao longo de décadas, cujas referências constam do inventário desenvolvido, apontam a folia de reis como uma das manifestações populares mais expressivas que formam o patrimônio cultural do Estado do Rio de Janeiro, razão pela qual se optou por proceder a seu mapeamento. Um dos motivos que coloca a folia de reis como forte candidata ao registro como patrimônio cultural imaterial brasileiro, além de sua importância atual como referência para grupos de diferentes comunidades do 
estado fluminense, é o fato de ser uma das mais antigas formas de Reisado existentes no Brasil. Apesar de sua maior incidência ocorrer nas regiões Sudeste e Centro-Oeste do país, enquanto integrante da "família" dos Reisados, trata-se de uma das expressões culturais mais presentes e representativas da identidade nacional brasileira.

A cada ano, a encenação da história bíblica refaz entre nós, brasileiros, o caminho seguido pelos Santos Reis no rumo de Belém. Os diversos momentos de recriação de textos bíblicos, através de adaptações textuais versadas, são fonte de patrimônio histórico, porque atualizam mitos e registram contextos históricos específicos. Portanto, além de lugares de sociabilidade entre foliões e devotos, as folias de reis são lugares de memória da cultura popular brasileira. Pierre Nora advoga que:

Os lugares de memória nascem e vivem do sentimento que não há memória espontânea, que é preciso criar arquivos, que é preciso manter aniversários, organizar celebrações, pronunciar elogios fúnebres, notariar atas, porque essas operações não são naturais. [...] Museus, arquivos, cemitérios e coleções, festas, aniversários, tratados, processos verbais, monumentos, santuários, associações, são marcos testemunhas de uma outra era, das ilusões de eternidade.12

Cada vez mais inserida em espaços urbanos a folia de reis passa a ser, na realidade contemporânea, identificada ao mundo rural e local, quando referida apenas ao passado. Nos tempos atuais, essa expressão de cultura fortemente identificada às camadas populares, é ressignificada em um presente também urbano e global.

A escolha dos lugares de memória nas cidades modernas tem importância crucial na definição da identidade cultural dos grupos que ali coabitam. Muito embora, "na cidade moderna o passado é muitas vezes um ciclo histórico já encerrado, do qual nem tudo pode ser conservado"13. Neste sentido, deve-se lembrar que o enfoque mais atual sobre patrimônio não se fundamenta exclusivamente na preservação de edificações de importância para momentos passados da história do país, mas envolve igualmente manifestações culturais atuais, que constituem o patrimônio cultural das elites e do povo, indistintamente, incluindo bens materiais e imateriais. Por isso, o inventário de expressões da cultura popular, como são as folias de reis, é uma ação significativa na construção da democracia plena em nosso país.

Por outro lado, devemos registrar que folias de reis são também um exemplo de confluência de saberes populares e eruditos, o que impossibilita análises dicotômicas. Pelo contrário, deve-se recordar que a aproximação entre universidade e estudos de cultura popular, então denominados estudos de folclore, se deu no Brasil a partir da primeira metade do século $X X$, isto é, "com a mudança do objeto de estudo da antropologia (do "diferente exótico" para o "outro próximo") que se criou espaço na universidade para a pesquisa de temas considerados folclóricos: festas populares, carnaval, culinária, dança, música, literatura, jogos, etc."14

\section{Resultados parciais e desdobramentos do projeto}

A participação de crianças, jovens, adultos e idosos revela os fundamentos da folia 
de reis, que perpassa séculos da história do Brasil. Sua prática, alicerçada em saberes e crenças transmitidas no seio de grupos e comunidades, está visceralmente vinculada à vida do próprio folião. Neste sentido, o projeto Inventário Nacional de Referências Culturais das Folias de Reis do Estado do Rio de Janeiro, desenvolvido pela UERJ com apoio do Iphan, poderá servir de subsídio para a efetivação de políticas públicas voltadas aos grupos de folias de reis de todo Brasil, colaborando para a efetivação da educação patrimonial no país e estimulando o diálogo dos órgãos municipais e estaduais com as comunidades detentoras de um saber tradicional de grande significado, como é o caso das folias de reis fluminenses.

Além de reconhecer as folias de reis fluminenses como dignas do recebimento do título de bem cultural do país, o inventário atesta a condição de valor patrimonial para os portadores dos saberes relativos a essa categoria de bem, sem dúvida inserida no consagrado patrimônio cultural imaterial brasileiro, tal como o jongo da Região Sudeste, as matrizes do samba carioca, o ofício das baianas de acarajé, o ofício de mestres de capoeira e a roda de capoeira, além da Festa do Divino Espírito Santo de Paraty, reconhecidos pelo Iphan em anos anteriores ${ }^{15}$.

Sem embargo, a titulação pode reverter o quadro total dos grupos encontrados no universo pesquisado, quando comparado com a realidade de décadas passadas. No município de Vassouras, por exemplo, houve diminuição no número de grupos de folias de reis em relação aos estudos realizados pelo Instituto Estadual do Patrimônio Cultural (Inepac) na década de 1980, quando foram identificados mais de 200 grupos em todo Estado do Rio de Janeiro. Essa redução pode ter acontecido, dentre outros fatores, devido à falta de apoio institucional de órgãos governamentais bem como à intolerância religiosa que, vigorando nos últimos tempos, deixa marcas profundas na cultura popular do país.

Portanto, ao legitimar a folia de reis como patrimônio cultural do Brasil, sua inclusão no quadro do patrimônio imaterial certamente contribuirá para garantir a manutenção dos grupos atuantes na atualidade, via o acesso a políticas públicas de cultura e educação, direito que, infelizmente, não chega a muitos foliões do Estado do Rio de Janeiro porque falta a estes o conhecimento específico para acesso, como o saber lidar com o preenchimento de formulários de editais públicos, por exemplo.

Em 2016, os documentos gerados pelo INRC, incluindo formulários devidamente preenchidos e um documentário etnográfico editado, com duração de 15 minutos, foram concluídos e encaminhados ao Iphan, subsidiando o pedido de registro, feito pelos próprios grupos fluminenses, para que a folia de reis seja reconhecida como patrimônio cultural do Brasil.

\section{Equipe técnica}

A equipe técnica de condução do projeto foi assim constituída:

Responsáveis pelo INRC: Mônica Costa (Iphan/RJ) e Ricardo Gomes Lima (Decult/UERJ); Supervisão de pesquisa: Cáscia Frade (Decult/UERJ);

Apoio técnico: Rejane Manhães (Decult/UERJ), Marcelo Vilarino e Maria Luiza Dias 
Oliveira (Iphan/RJ);

Estudantes de graduação / Bolsistas Cultura encarregados da pesquisa de fontes documentais: Jessica Tamara e Tereza Torres (Decult/UERJ);

Estudantes de graduação / Bolsistas de Extensão (Bolsa Internato Rural) encarregados da pesquisa de campo nos municípios: Carolina Guarilha, Catiane Silva, Clarice Duarte, Felipe Sá, Mariana Rocha, Paulo Cabral e Thiago Silvestre (Decult/UERJ);

Pesquisadoras voluntárias: Martha Pontes e Rosane Assis;

Parceiros integrantes de órgãos de cultura de municípios fluminenses: Ivan Cid (Itaboraí), Jomar Dias (Santa Maria Madalena), Paulo Henrique de Andrade e Sônia Cardoso (Casimiro de Abreu).

\section{Referências}

1. CASTRO, Zaíde Maciel de; COUTO, Aracy do Prado. Folia de Reis. Rio de janeiro: MEC-SEC: FUNARTE: Instituto Nacional do Folclore, 1977.

2. CELLULARE, Luiz Henrique; CANASSA, Flávio Arduini. Em nome de Santos Reis: um estudo sobre Folias de Reis em Uberaba. v.1. Uberaba, MG: Arquivo Público de Uberaba, 1997: 5.

3. AMARAL, Amadeu. Tradições populares. São Paulo: Instituto Progresso, 1948.

4. CARNEIRO, Edison. Folguedos tradicionais. Rio de Janeiro: Conquista, 1974.

5. CASTRO, Zaíde Maciel de; COUTO, Aracy do Prado. Folia de Reis. Rio de janeiro: MEC-SEC: FUNARTE: Instituto Nacional do Folclore, 1977.

6. BRANDÃO, Carlos Rodrigues. Memória do sagrado: estudos de religião e ritual. São Paulo, Editora Paulinas, 1985: 137.

7. BITTER, Daniel. A bandeira e a máscara: estudo sobre a circulação de objetos rituais nas folias de reis. Rio de Janeiro: UFRJ, IFCS, 2010:111.

8. BRANDÃO, Carlos Rodrigues. A folia de reis de Mossâmedes. Rio de Janeiro: FUNARTE, 1977.

9. LAPLANTINE, François. Aprender Antropologia. São Paulo: Brasiliense, 1997: 42.

10. OLIVEIRA, Ana Gita de. O INRC como Instrumento de Políticas de Preservação do Patrimônio Cultual Imaterial: a Experiência Brasileira. Disponível em: http://portal. iphan.gov.br/uploads/ckfinder/arquivos/artigo_boiBumba_AExperienciaBrasiliera_ AnaGitaOliveira.pdf. Acesso em 30/03/2017.

11. MALINOWSKI, Bronislaw K. Argonautas do Pacífico Ocidental: um relato do empreendimento e da aventura dos nativos nos arquipélagos da Nova Guiné melanésia. 2 ${ }^{a}$ ed. São Paulo: Abril Cultural, 1978.

12. NORA, Pierre. Entre memória e história: a problemática dos lugares. Projeto História. São Paulo: PUC-SP. No 10, 1993: 12.

13. ARGAN, Giulio Carlo. História da Arte como história da cidade. São Paulo: Martins Fontes, 1995: 77.

14. FRADE, Maria de Cáscia. Folclore/Cultura Popular: Aspectos de sua História. Disponível em: http://www.unicamp.br/folclore/Material/extra_aspectos.pdf . Acesso 
em: 20 de novembro de 2015.

15. VIEIRA, Isabela. Debate em cidade do Rio retoma proposta de registro imaterial da folia de reis. Disponível em: http://www.ebc.com.br/noticias/brasil/2014/09/debate-em-cidade-do-rio-retoma-proposta-de-registro-imaterial-da-folia-de. Acesso em 15 de maio de 2015. 